\title{
Blood-Borne Amyloid- $\beta$ Dimer Correlates with Clinical Markers of Alzheimer's Disease
}

\author{
Victor L. Villemagne, ${ }^{1,2,3}$ Keyla A. Perez, ${ }^{1,4,5}$ Kerryn E. Pike, ${ }^{1,2}$ W. Mei Kok, ${ }^{4,5,6}$ Christopher C. Rowe, ${ }^{2,3}$ \\ Anthony R. White, ${ }^{1,5}$ Pierrick Bourgeat, ${ }^{8}$ Olivier Salvado, ${ }^{8}$ Justin Bedo, ${ }^{7}$ Craig A. Hutton,,${ }^{4,6}$ Noel G. Faux, ${ }^{1,8}$ \\ Colin L. Masters, ${ }^{1}$ and Kevin J. Barnham ${ }^{1,4,5}$ \\ ${ }^{1}$ Mental Health Research Institute, The University of Melbourne, Parkville, Melbourne, Victoria 3052, Australia, ${ }^{2}$ Department of Nuclear Medicine and \\ Centre for PET, and ${ }^{3}$ Department of Medicine, Austin Health, Heidelberg, Victoria 3084, Australia, ${ }^{4}$ Bio21 Molecular Science and Biotechnology Institute, \\ Departments of ${ }^{5}$ Pathology and ${ }^{6}$ Chemistry, and ${ }^{7}$ Victorian Research Laboratory, National ICT Australia, The University of Melbourne, Parkville, \\ Melbourne Victoria 3010, Australia, and ${ }^{8}$ CSIRO Preventative Health National Research Flagship ICTC, The Australian e-Health Research Centre, \\ BioMedIA, Herston, Queensland 4029, Australia
}

\begin{abstract}
Alzheimer's disease (AD) is the most common age-related dementia. Unfortunately due to a lack of validated biomarkers definitive diagnosis relies on the histological demonstration of amyloid- $\beta(\mathrm{A} \beta)$ plaques and tau neurofibrillary tangles. $\mathrm{A} \beta$ processing is implicated in $\mathrm{AD}$ progression and many therapeutic strategies target various aspects of this biology. While $\mathrm{A} \beta$ deposition is the most prominent feature of $\mathrm{AD}$, oligomeric forms of $\mathrm{A} \beta$ have been implicated as the toxic species inducing the neuronal dysfunction. Currently there are no methods allowing routine monitoring of levels of such species in living populations. We have used surface enhanced laser desorption ionization time of flight (SELDI-TOF) mass spectrometry incorporating antibody capture to investigate whether the cellular membranecontaining fraction of blood provides a new source of biomarkers. There are significant differences in the mass spectra profiles of AD compared with $\mathrm{HC}$ subjects, with significantly higher levels of $\mathrm{A} \beta$ monomer and dimer in the blood of AD subjects. Furthermore, levels of these species correlated with clinical markers of $\mathrm{AD}$ including brain $\mathrm{A} \beta$ burden, cognitive impairment and brain atrophy. These results indicate that fundamental biochemical events relevant to $\mathrm{AD}$ can be monitored in blood, and that the species detected may be useful clinical biomarkers for $\mathrm{AD}$.
\end{abstract}

\section{Introduction}

Alzheimer's disease (AD) is the most common age-related dementia. However, due to a lack of validated biomarkers definitive diagnosis still relies on postmortem histological demonstration of amyloid- $\beta(\mathrm{A} \beta)$ plaques and tau neurofibrillary tangles (Masters et al., 2006). Genetic studies have implicated $A \beta$ processing in the progression of $\mathrm{AD}$, and while $\mathrm{A} \beta$ deposition is the most prominent feature of $\mathrm{AD}, \mathrm{A} \beta$ plaque load does not necessarily correlate with disease severity (McLean et al., 1999). A $\beta$ peptides are generated from the cleavage of the amyloid precursor protein (APP), by the proteases $\beta$ - and $\gamma$-secretases (Masters et al., 2006).

The clinically useful methods for monitoring $\mathrm{A} \beta$ species in vivo are either in the CSF via ELISA methods using antibodies raised against monomeric A $\beta$ (Sjögren et al., 2003) or via positron emission tomography (PET) imaging using the radioactive ${ }^{11} \mathrm{C}$-labeled Pittsburgh compound B (PIB) to measure the deposited $\mathrm{A} \beta$ burden in the brain (Klunk et al., 2004; Rowe et al., 2007). Neither the monomeric nor fibrillar forms of $A \beta$ are thought to be responsible for the toxicity associated with $\mathrm{A} \beta$

Received Oct. 18, 2009; revised March 14, 2010; accepted March 19, 2010. This work was funded by National Health and Medical Research Council of Australia (NHMRC).

Correspondence should be addressed to Kevin J. Barnham, Level 4, Bio21 Institute, 30 Flemington Road, Parkville, VIC 3010, Australia. E-mail: kbarnham@unimelb.edu.au.

D0I:10.1523/JNEUROSCI.5180-09.2010

Copyright $\odot 2010$ the authors $\quad 0270-6474 / 10 / 306315-08 \$ 15.00 / 0$
(Cappai and Barnham, 2008). Recent studies have implicated oligomeric forms of $A \beta$ as the toxic species that induce the neuronal dysfunction associated with AD (Walsh et al., 2002; Walsh and Selkoe, 2004; Shankar et al., 2008). These species include synaptotoxic $\mathrm{A} \beta$ dimers isolated from postmortem $\mathrm{AD}$ brain tissue (Shankar et al., 2008). To date, there is no method for monitoring such species in living subjects, although an ELISA assay for detecting oligomeric $\mathrm{A} \beta$ has recently been described (Xia et al., 2009).

APP is a ubiquitously expressed type 1 transmembrane protein found in all tissues including blood. Traditionally, when blood is collected and fractionated for diagnostic purposes, plasma and/or serum is analyzed while the pellet containing cellular elements (CEs); i.e., erythrocytes, leukocytes and platelets; is discarded. Although a recent longitudinal study found that higher plasma $A \beta 42$ levels at the onset of the study were associated with a threefold increased risk of AD (Schupf et al., 2008), attempts to use plasma $\mathrm{A} \beta$ levels as a biomarker for $\mathrm{AD}$ have, at best, generated variable results (Zetterberg and Blennow, 2006).

Not only is APP a transmembrane protein but so are the proteases that generate $A \beta$ and a range of studies have shown that many of the deleterious biological effects attributable to $A \beta$ are due to the interaction of oligomeric neurotoxic $\mathrm{A} \beta$ peptides with cell membranes (Glabe and Kayed, 2006; Hung et al., 2008). Therefore, given that most APP/A $\beta$ pathology seems to be driven by membrane interactions - and $\mathrm{A} \beta$ oligomers have a higher af- 
finity for lipid membranes (Hung et al., 2008)—we investigated whether the usually discarded membrane-rich CE fraction may contain oligomeric $\mathrm{A} \beta$ species that correlate with markers of $\mathrm{AD}$ severity.

\section{Materials and Methods}

Participants. The blood of 118 participants was analyzed for the study. Fifty-two elderly individuals with well documented normal cognitive function, 43 patients with mild to moderate $\mathrm{AD}$, and 23 subjects with MCI were recruited for the study (Table 1). Clinical classification was based on the clinical interview, Mini-Mental State Examination (MMSE) and clinical dementia rating (CDR). All $\mathrm{AD}$ patients met National Institute of Neurological and Communicative Disorders and Stroke-Alzheimer's Disease and Related Disorders Association criteria for probable AD (McKhann et al., 1984). MCI subjects met the Petersen criteria of subjective and objective cognitive difficulties, predominantly affecting memory, in the absence of dementia or significant functional loss (Petersen et al., 1999). All patients were recruited from the Austin Health Memory Disorders and Neurobehavioural Clinics or the Healthy Aging Study (Mental Health Research Institute). None of the participants were receiving, nor ever received, anti-A $\beta$ medication. Written informed consent was obtained before participation. Approval for the study was obtained from the Austin Health Human Research Ethics Committee.

Blood sample preparation. Whole blood was collected by phlebotomy in EDTA vacutainers $\left(6 \mathrm{ml}\right.$ of $\mathrm{K}_{3}$ EDTA, Greiner Bio-One) and processed within $20 \mathrm{~min}$ of procurement. Vacutainers were spun at $3500 \mathrm{rpm}(1.9 \mathrm{~g})$ at $4^{\circ} \mathrm{C}$ for $30 \mathrm{~min}$. The upper layer of plasma was then removed and small aliquots of $100 \mu \mathrm{l}$ were made and store at $-80^{\circ} \mathrm{C}$ for possible future use. The material remaining in the tube was then homogenized using a vortex and after this $100 \mu \mathrm{l}$ aliquots were made and stored at $-80^{\circ} \mathrm{C}$ for future use.

Each aliquot was used just once by combining $10 \mu \mathrm{l}$ of this material (CEs) with $10 \mu \mathrm{l}$ of urea $8 \mathrm{M}$, and $120 \mu \mathrm{l}$ of $0.5 \%$ Triton X-100 in PBS, and placed for $15 \mathrm{~min}$ in an ultra-sound bath with ice (each sample was done by duplicate) $130 \mu \mathrm{l}$ of this mixture were added per spot to be analyzed.

Surface enhanced laser desorption ionization-time of flight mass spectrometry. PS10 ProteinChip arrays (Bio-Rad) were used for the SELDITOF (surface enhanced laser desorption ionization time of flight) mass spectrometry (MS). Specific antibodies ( $2 \mu$ l of either $4 \mathrm{G} 8$ or WO2) were added to the arrays in PBS $(0.25 \mathrm{mg} / \mathrm{ml})$. To confirm that the binding observed was not due to nonspecific binding control spectra using a nonspecific IgG antibody were also obtained. Chips were then incubated overnight at $4^{\circ} \mathrm{C}$ in a humidity chamber.

Excess antibodies were then removed and blocking buffer $(0.5 \mathrm{M}$ ethanolamine in PBS) was added $(5 \mu \mathrm{l})$ and arrays were incubated for 30 min. After the removal of the blocking buffer, each array was washed for $5 \mathrm{~min}$ with $50 \mu \mathrm{l}$ of $0.5 \%$ Triton X-100/PBS (wash-buffer). The solvent was then removed, and the arrays were washed for 5 min with $50 \mu \mathrm{l}$ of PBS. All biological samples were analyzed in triplicate. Individual samples $(130 \mu \mathrm{l})$ were added to each spot and the arrays were incubated at room temperature for $3 \mathrm{~h}$. The excess sample was then removed, and each spot was washed twice with $100 \mu \mathrm{l}$ of wash-buffer for $10 \mathrm{~s}$, followed by a wash with $100 \mu \mathrm{l}$ of PBS twice for $10 \mathrm{~s}$ as well. Finally, the arrays were washed twice with $100 \mu \mathrm{l}$ of HEPES $1 \mathrm{~mm}$ for $10 \mathrm{~s}$. The array was then air-dried. One microliter of sinapinic acid (SPA, 50\% saturated in 50\% $(\mathrm{v} / \mathrm{v})$ acetonitrile and $0.5 \%$ in TFA) was applied to each spot twice. The array was air-dried between each application. All incubations and washes were performed on a shaking table.

Chips were analyzed in a PBSIIC, SELDI-TOF mass spectrometer, and spectra analyzed using Ciphergen ProteinChip software 3.1. The distributions of the mass to charge ratio $(\mathrm{m} / \mathrm{z})$ peak intensities in the spectra
Table 1. Demographics: participants [means (SD) for groups by classification]

\begin{tabular}{lccc}
\hline & $\mathrm{HC}(n=52)$ & $\mathrm{MCl}(n=23)$ & $\mathrm{AD}(n=43)$ \\
\hline Age (years) & $73.2(7.7)$ & $70.9(9.6)$ & $72.7(10.7)$ \\
MMSE & $29.0(1.1)$ & $26.3(2.4)^{*}$ & $21.8(4.1)^{*}$ \\
Male/female & $25 / 27$ & $9 / 14$ & $20 / 23$ \\
\% ApoE $\epsilon 4$ & $29 \%$ & $48 \%^{\dagger}$ & $73 \%^{\dagger}$ \\
Composite memory & $-0.1(0.9)$ & $-2.4(1.0)^{*}$ & $-3.4(0.6)^{*}$ \\
Composite frontal & $0.1(0.7)$ & $-0.9(0.6)^{*}$ & $-1.8(0.9)^{*}$ \\
Gray matter volume & $0.31(0.01)$ & $0.29(0.01)^{*}$ & $0.29(0.01)^{*}$ \\
Neocortical PiB SUVR & $1.4(0.4)$ & $1.9(0.6)^{*}$ & $2.3(0.4)^{*}$ \\
\hline
\end{tabular}

*Significantly different from controls $(p<0.05)$.

†Significantly different from controls (Fisher's exact test $p<0.05)$.

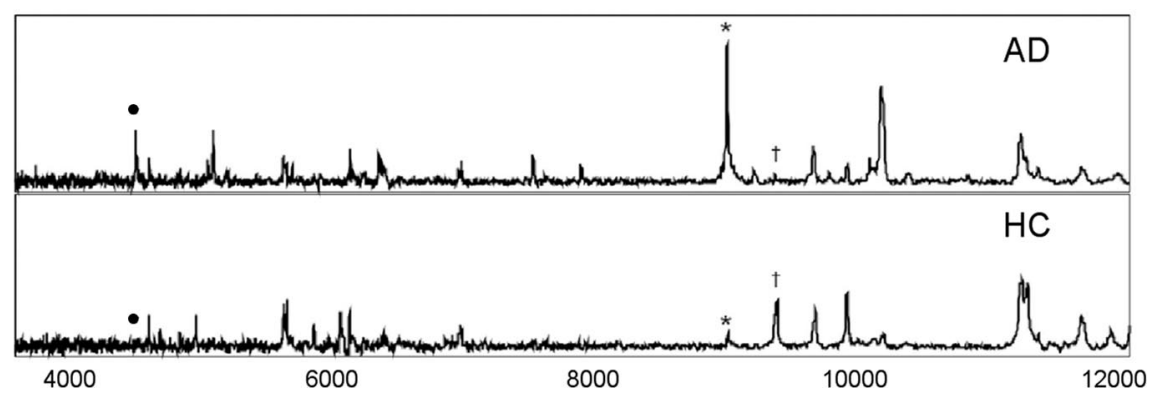

Figure 1. Representative SELDI-TOF/MS spectra. Samples extracted from the CE of blood from an AD subject (top) and a norma age-matched control (bottom). In these examples the antibody W02 was used. Peaks marked with are $A \beta_{42}$ and the corresponding dimer $\left({ }^{*}\right)$, respectively, are elevated in AD. In contrast, the 9962 Da peak (†) is elevated in HC.

\begin{tabular}{|c|c|c|c|}
\hline \multicolumn{2}{|l|}{ W02 } & \multicolumn{2}{|l|}{$4 \mathrm{G} 8$} \\
\hline Peak $m / z$ & $p$ & Peak $m / z$ & $p$ \\
\hline 4529 & 0.07 & & \\
\hline 4625 & 0.003 & & \\
\hline 5289 & 0.028 & & \\
\hline 9058 & $<0.001$ & 9058 & 0.001 \\
\hline 9962 & 0.002 & & \\
\hline 10293 & 0.004 & 10292 & 0.034 \\
\hline 11310 & 0.001 & 11310 & 0.044 \\
\hline 11346 & 0.001 & & \\
\hline 11432 & 0.014 & & \\
\hline 12310 & 0.002 & 12310 & 0.024 \\
\hline 12768 & 0.003 & & \\
\hline 12834 & 0.008 & & \\
\hline 15315 & 0.07 & & \\
\hline 15524 & 0.06 & & \\
\hline
\end{tabular}

showed skewness to either left or right. By taking the logarithm of the peak intensities, skewness was substantially reduced, and the distributions met criteria for normality. To demonstrate that the detected peak intensities are dependent on sample concentration, linear standard curves of concentration versus peak intensity were constructed for synthetic $\mathrm{A} \beta$ and the $\mathrm{A} \beta_{1-42} \mathrm{Met}_{35}(\mathrm{O})$ dimer (see supplemental material, available at www.jneurosci.org).

Preparation of $A \beta_{1-42} \mathrm{Met}_{35}(\mathrm{O})$ dimer. Resin-bound $\mathrm{A} \beta_{11-42} \operatorname{Met}_{35}(O)$ was prepared according to standard methods (Tickler et al., 2001; Barnham et al., 2003). Dityrosine was prepared according to the previously reported method (Barnham et al., 2004; Skaff et al., 2005). Fmoc protection of dityrosine and incorporation into SPPS of the $\mathrm{A} \beta_{1-42} \operatorname{Met}_{35}(O)$ dimer was performed according to the previously reported method (Kok et al., 2009).

Genotyping. ApoE genotype was determined by PCR amplification of genomic DNA.

Neuropsychological assessments. All subjects undertook a variety of neuropsychological tasks, designed to assess a broad range of cognitive 
A

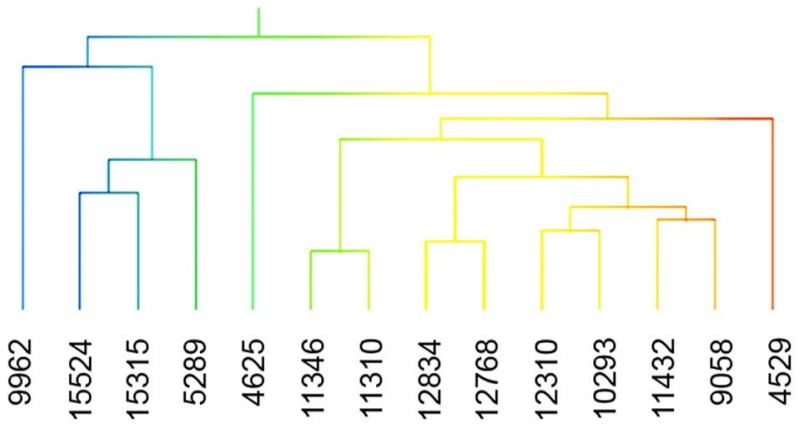

health

B

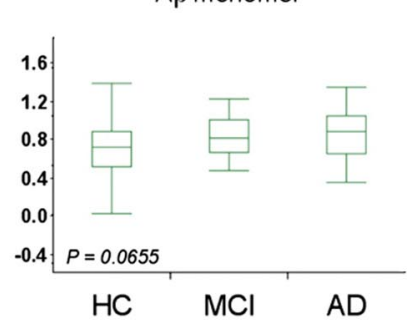

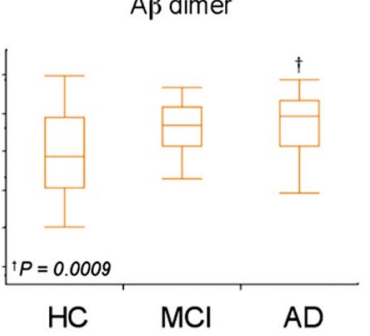

disease

$9962 \mathrm{Da}$

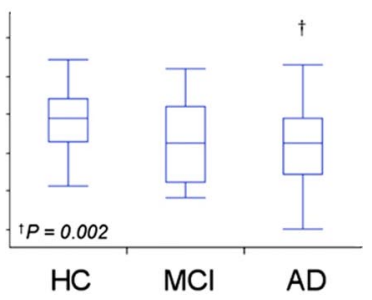

Figure 2. Distribution of blood SELDI-TOF MS values in regards to mass to charge ratio and clinical classification in 118 participants. Hierarchical cluster analysis showing two distinct classes of peaks associated with the normal or abnormal processing of APP. A, At the left end, peak $9962 \mathrm{Da}$, a species that was higher in HC than in AD. On the right end of the cluster are peaks due to the $A \beta$ monomer and dimer that were higher in $A D$. The pattern of the cluster analysis is consistent with two different processing pathways for APP: an amyloidogenic pathway that is elevated in AD and a non-amyloidogenic pathway that is elevated in the control subjects. Box-and-whiskers plots comparing the intensities of $\mathrm{A} \beta$ monomer, dimer, and the peak at $9962 \mathrm{Da}$ in $\mathrm{HC}, \mathrm{MCl}$, and $A D$ subjects. $B, A$ good separation is observed between the $A D$ and $H C$ groups (Cohen's d: 0.41, 0.76 and 0.73 for monomer, dimer and 9962 Da peak, respectively).

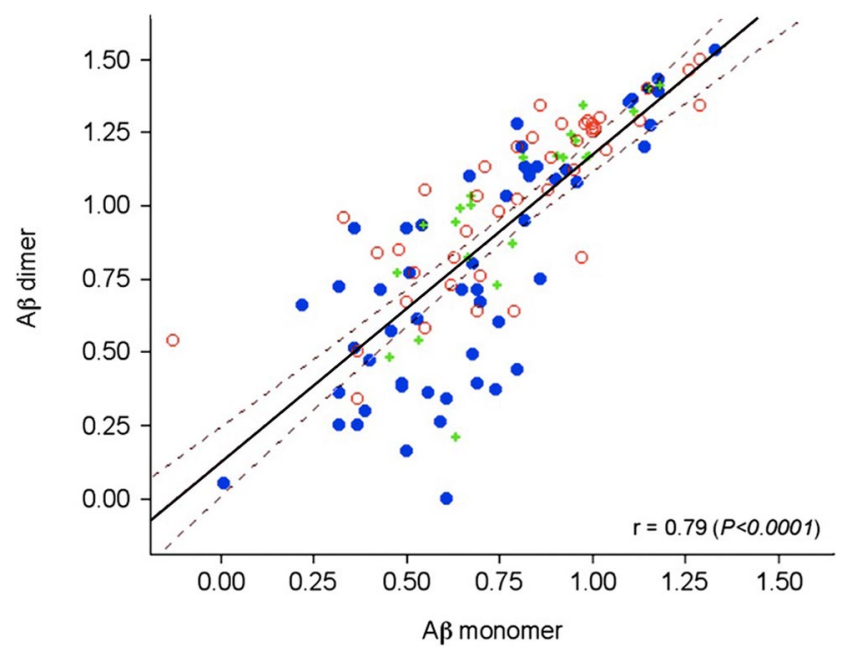

Figure 3. Correlation between $A \beta 42$ monomer and dimer. The intensities of the peaks assigned to the monomeric $A \beta 42$ and the corresponding dimer from 118 participants are highly correlated ( $r=0.79, p<0.0001)$. HC, Blue circle; $M C l$, green $+; A D$, red circle.

domains commonly affected by $\mathrm{AD}$ and aging. In addition to the MMSE and CDR, episodic memory was assessed using delayed recall of the California Verbal Learning Test-Second edition (CVLT-II), and the Rey Complex Figure Test (RCFT), while executive function was measured using letter fluency, category fluency, verbal fluency switching task, and the incongruent condition of the Stroop task. Using the neuropsychological test results of 65 healthy older people with negative PiB and normal MRI scans as the reference, a composite episodic memory score was

generated by taking the average of the $Z$ scores for the memory tasks (Pike et al., 2007), and a composite executive function score was generated by taking the average of the $Z$ scores for the executive function tasks.

Neuroimaging. All subjects underwent a 3D spoiled gradient echo (SPGR) T1-weighted MRI acquisition for screening, quantification of gray matter atrophy, and subsequent coregistration with the PET images. As described previously (Ourselin et al., 2001), T1-weighted MR images for each subject were classified into gray matter (GM), white matter (WM), and CSF using an implementation of the expectation maximization segmentation algorithm. The Montreal Neurological Institute (MNI) single-subject MRI brain template (Collins et al., 1998) and corresponding Automated Anatomical Labeling (AAL) template (TzourioMazoyer et al., 2002) and tissues priors were spatially normalized to each participant to automatically obtain a parcellation for each selected atlas into GM, WM, and CSF. The measured gray matter volumes were normalized for head size using the total intracranial volume, defined as the sum of GM, WM, and CSF volumes. The volume results are presented as the proportion of total intracranial volume.

Production of ${ }^{11} \mathrm{C}-\mathrm{PiB}$ and PiB-PET scans were performed at the Centre for PET, Austin Hospital, as previously described (Rowe et al., 2007). Briefly, a 30 min acquisition emission PET scan was acquired starting at $40 \mathrm{~min}$ after the administration of $370 \mathrm{MBq}$ of ${ }^{11} \mathrm{C}-\mathrm{PiB}$. Regional Standardized Uptake Value (SUV), defined as the decay-corrected brain radioactivity concentration, corrected for injected dose and body weight, was normalized to the cerebellar cortex to obtain SUV Ratios (SUVR) (Rowe et al., 2007). Neocortical A $\beta$ burden was expressed as the average SUVR of the area-weighted mean for the following cortical regions of interest: frontal (consisting of dorsolateral prefrontal, ventrolateral prefrontal, and orbitofrontal regions), superior parietal, lateral temporal, lateral occipital, and anterior cingulate and posterior cingulate.

Statistical analysis. Continuous variables for the groups were tested for normality of distribution using the Shapiro-Wilk test and visual inspection of variable histograms. Statistical evaluations were performed using ANOVA for all spectrum peaks, using false discovery rate (FDR) (Benjamini and Hochberg, 1995) to select the peaks that were different between groups. The selected peaks for each group were then compared using ANOVA, followed by a Dunnet's test to compare each group with controls, and a Tukey-Kramer HSD test to establish differences between group means. Categorical differences were evaluated using Fisher's exact test. Pearson product-moment correlation analyses were conducted between the different variables. Assessment of the robustness of the correlations was performed via tenfold leave- $10 \%$-out cross-validation. To investigate the patterns and interrelationships between the series of spectrum peaks, a hierarchical cluster analysis using an average linkage method was performed (Sokal and Michener, 1958). In all instances statistical significance was defined as $p<0.05$. Multiple comparisons were controlled for with a FDR. Data are presented as mean \pm SD unless otherwise stated.

\section{Results}

Demographic, clinical, neuropsychological, and neuroimaging characteristics of the 118 participants are reported in Table 1. There were significant differences between the healthy older control ( $\mathrm{HC}), \mathrm{AD}$, and Mild Cognitive Impairment (MCI) groups in 
MMSE and cognitive composite scores. The AD group had a higher prevalence $(>70 \%)$ of ApoE $\varepsilon 4$ allele carriers. There was no significant difference in age or in gender distribution between groups.

\section{Mass spectra profiles for cellular elements are different between $\mathrm{AD}$ and control}

Blood was collected from all participants and fractionated into plasma and CE which were then extracted with an aqueous solution of urea and Triton X-100. The purpose of adding a denaturant and detergent was to break up any potential protein/protein or protein/membrane interactions involving any $\mathrm{APP} / \mathrm{A} \beta$ fragments. A variety of denaturants and detergents were assessed over a large concentration range to identify the conditions that reproducibly gave the best signal-to-noise in the mass spectra. The extracted material was then analyzed in triplicate by SELDI-TOF MS, with the operator blinded to the disease status of the subjects, using antibody capture (WO2 epitope $\mathrm{A} \beta$ residues $4-8$ and $4 \mathrm{G} 8$ epitope $\mathrm{A} \beta$ residues $17-21)$. These are generic anti-A $\beta$ antibodies able to capture most $\mathrm{A} \beta$ species.

The spectra of the CE material from all subjects contained a large number of peaks; with $\mathrm{m} / \mathrm{z}$ ranging from 3.5 to 16.0 $\mathrm{kDa}$; consistent with a variety of $\mathrm{APP} / \mathrm{A} \beta$ fragments present in the CE. Moreover, the spectra obtained from $\mathrm{AD}$ subjects were substantially different to that of the $\mathrm{HC}$, and $>10$ peaks showed significant differences between the two groups (Fig. 1 shows representative examples). The $\mathrm{m} / \mathrm{z}$ values of the peaks with intensities that were found to be significantly different between the $\mathrm{HC}$ and $\mathrm{AD}$ groups are listed in Table 2. SELDI-TOF MS of the plasma fraction did not resolve any peaks that were significantly different between the control and disease groups; nor were any peaks due to species normally associated with $\mathrm{AD}$ (i.e., $\mathrm{A} \beta$ ) observed (data not shown).

\section{$\mathrm{A} \boldsymbol{\beta}$ dimers are elevated in $\mathrm{AD}$ blood}

Hierarchical clustering of the CE WO2 dataset is shown in Figure $2 \mathrm{~A}$. At one end of the cluster analysis are a number of peaks that were elevated in $\mathrm{AD}$ with $\mathrm{m} / \mathrm{z}$ ratios that are consistent with species prominent in the amyloidogenic pathway commonly associated with $\mathrm{AD}$, including $\mathrm{A} \beta 42$ (the $m / z$ of 4529 is consistent with an oxidized form of $A \beta$; i.e., the calculated molecular weight of $\mathrm{A} \beta 42$ is $4513 \mathrm{Da}$ plus 16 from an oxygen atom). The intensities of the peaks due to $\mathrm{A} \beta 42$ are $16 \%$ higher in the $\mathrm{AD}$ subjects compared with the controls (Fig. $2 \mathrm{~B}$ ); while there is a strong trend this increase in monomeric $A \beta$ levels did not reach statistical significance. However, the peak with a $m / z$ of 9058 Da corresponding to the mass of an $\mathrm{A} \beta 42$ dimer was found to be significantly increased in $\mathrm{AD}$ compared with control subjects $(35 \%$ higher $p<0.001)$ (Fig. $2 B$ ). There was a strong correlation between the amount of monomeric $\mathrm{A} \beta 42$ detected and the corresponding dimer $(r=$ $0.79, p<0.0001$ ) (Fig. 3). The dimer peak was also significantly higher in the CE of $\mathrm{AD}$ patients when $4 \mathrm{G} 8$ was used as the capture antibody (Table 2). While definitive identification of the species responsible for the various peaks will require high resolution MS/MS data, to more confidently characterize that the peaks at $\mathrm{m} / z 4529$ and 9058 corresponded to A $\beta 42$ species, SELDI-TOF spectra were collected using the antibodies G210 (A $\beta 40$ specific) and G211 (A $\beta 42$ specific) (Ida et al., 1996). As shown in Figure $4 A$, the peaks that were assigned to $\mathrm{A} \beta 42$ and the corresponding dimer were detected by three different $A \beta$ antibodies (4G8, WO2, G211) but were not detected by the $A \beta 40$-specific antibody G210. To further characterize the $A \beta$ dimer we synthesized an oxidized $\mathrm{A} \beta$ dimer (the sulfur atom of Met35 is oxidized to a sulfoxide) where the two $\mathrm{A} \beta$ peptide chains are covalently cross-linked with a dityrosine moiety at residue number 10. As can be seen from Figure $4 B$ the SELDI MS of the Mwt of this synthetic dimer is the same as the $m / z$ of the dimer elevated in $\mathrm{AD}$ blood.

At the opposite end of the cluster analysis (Fig. $2 \mathrm{~A}$ ) are a group of peaks that were decreased in $\mathrm{AD}$ compared with control; the largest difference being for a peak with a $\mathrm{m} / z$ of $9962 \mathrm{Da}$ which was significantly decreased in $\mathrm{AD}$ compared with $\mathrm{HC}$ by $56 \%$ $(p=0.002)$ (Fig. $2 B$ ). This molecular weight is too small to be the result of $\beta$-secretase activity, and too big to be the result of $\gamma$-secretase activity, suggesting an alternative, non-amyloidogenic processing pathway. The observed distribution in the cluster analysis (Fig. $2 \mathrm{~A}$ ) is consistent with the notion that there are 

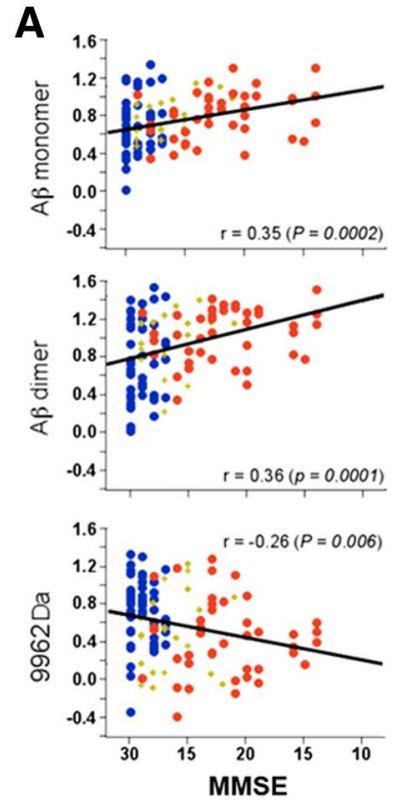

B

$A \beta$ monomer

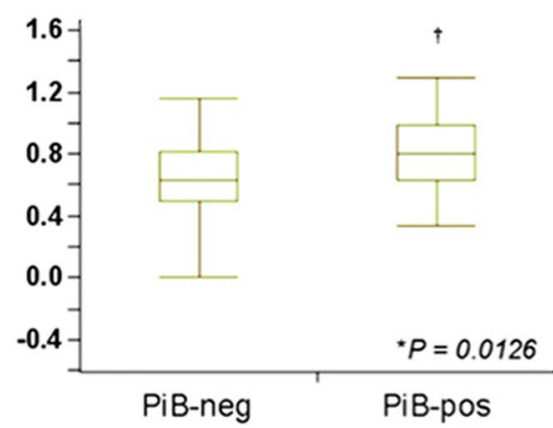

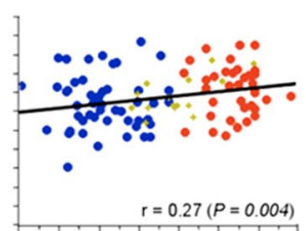
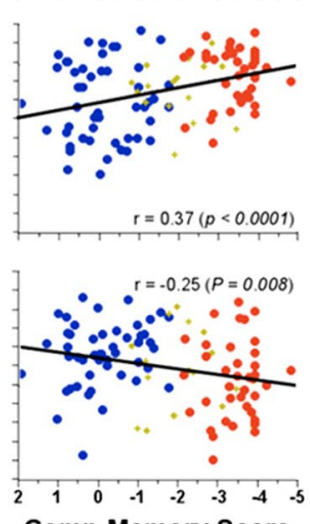

Comp Memory Score
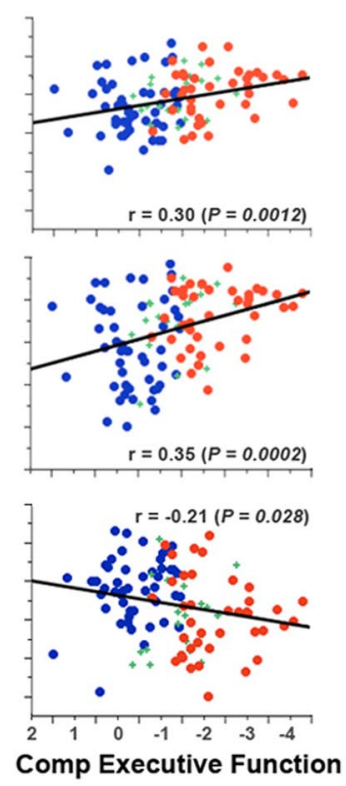

$A \beta$ dimer

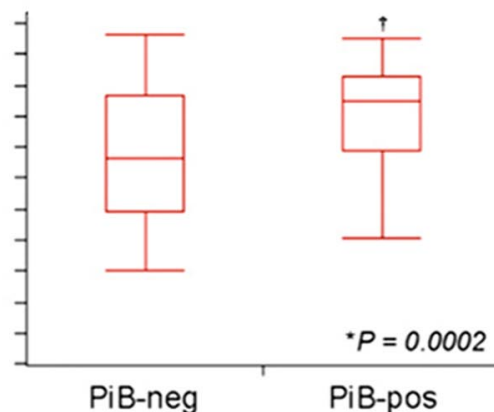

PiB-neg
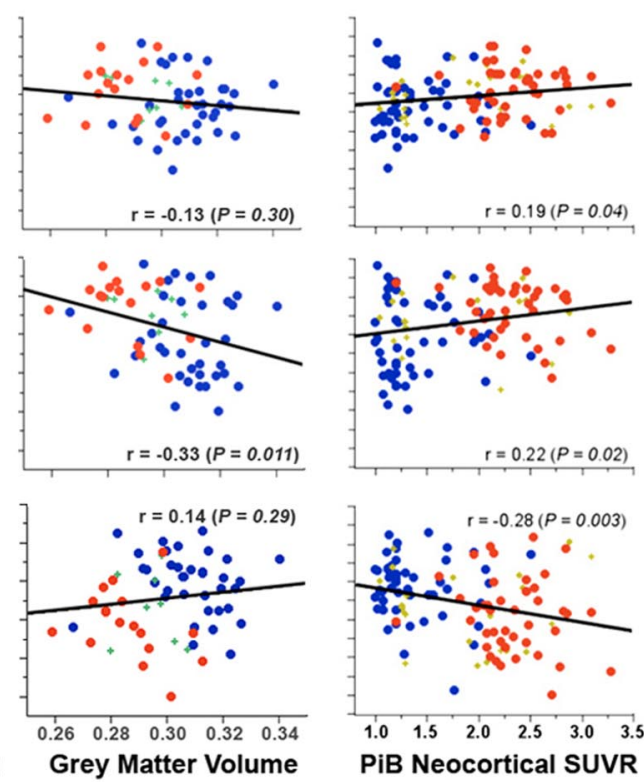

9962 Da

Figure 5. Relationship between blood SELDI-TOF MS mass to charge ratios and clinical and neuroimaging parameters. A $\beta$ monomer, dimer and 9962 Da are highly correlated with clinical, neuropsychometric and biological markers, such as MMSE, memory performance, executive function, gray matter volume, and brain A $\beta$ burden as measured by PiB-PET, underlying their interrelationship. $\boldsymbol{A}$, These graphs reflect the balance in APP processing between the amyloidogenic and non-amyloidogenic pathway that defines $A D$. $H C$, Blue circle; $M C l$, green $+; A D$, red circle. Box-and-whiskers plots of the intensities of $A \beta$ monomer, dimer, and 9962 with brain $A \beta$ burden as measured by PiB PET. $B, A$ PiB SUVR threshold of 1.45 was used to separate the groups in PiB-positive (PiB-pos) and PiB-negative (PiB-neg).

differential processing pathways for APP between diseased and healthy subjects.

\section{APP/A $\beta$ biomarkers correlate with clinical measures of AD}

Not only are the $\mathrm{A} \beta$ monomer and dimer elevated in $\mathrm{AD}$ blood compared with controls, but there are correlations between the levels of these species in the blood and other clinical, neuropsychometric, and biological markers of AD. These include MMSE $(r=0.35$ and $0.36, p=0.0002$ and 0.0001 , for monomeric and dimeric $\mathrm{A} \beta$, respectively), memory impairment ( $r=0.27$ and $0.37, p=0.004$ and $<0.0001$, for monomer and dimer respectively), executive function $(r=0.30$ and $0.35, p=0.0012$ and 0.0002 , for monomer and dimer respectively), gray matter volume ( $r=-0.33, p=0.011$, for the dimer), and brain A $\beta$ burden as measured by PET imaging using ${ }^{11} \mathrm{C}-\mathrm{PiB}(r=0.19$ and 0.22 , $p=0.04$ and 0.02 , for monomer and dimer respectively) (Fig. $5 A$ ). Cross-validation of these results showed the robustness of the findings, with cross-validated correlation coefficients $\left(q^{2}\right)$ being on average $7 \%$ and $15 \%$ worse than significant non-crossvalidated correlation coefficients $\left(r^{2}\right)$ values for monomer and dimer ratios, respectively, being better for neuropsychometric measures than for neuroimaging parameters (6\% vs $23 \%$, respectively). No correlations were found when the clinical groups were examined separately.

Furthermore, all the subjects including the MCI group were separated into $\mathrm{PiB}$-positive and $\mathrm{PiB}$-negative groups using a Neocortical SUVR threshold of 1.45 , obtained by unbiased statistical approaches such as hierarchical cluster analysis or partition models for the determination of a Neocortical PiB 'cutoff level applied to the HC group. Using this threshold, $98 \%$ of $\mathrm{AD}, 57 \%$ of MCI and $35 \%$ of HC were classified as PiB-positive. Both the monomer $(p=0.013)$ and dimer $(p=0.0002)$ are significantly elevated within the $\mathrm{PiB}$-positive group when compared with the negative group (Fig. 5B).

There are also significant correlations between $\mathrm{m} / z 9962 \mathrm{Da}$ and the clinical neuropsychometric (respectively $r=-0.26(p=$ $0.006) ; 0.25$ ( $p=0.008) ;-0.21$ ( $p=0.028)$ for MMSE, memory impairment, and executive function) and brain $\mathrm{A} \beta$ burden $r=$ $-0.28(p=0.003)$ (Fig. $5 A$ ). As with the monomer and dimer peaks, no correlation was found when the clinical groups were examined separately. The $9962 \mathrm{~m} / z$ peak was significantly ( $p=$ 0.005 ) elevated in the PiB-negative group (Fig. $5 B$ ). As this peak is 
A

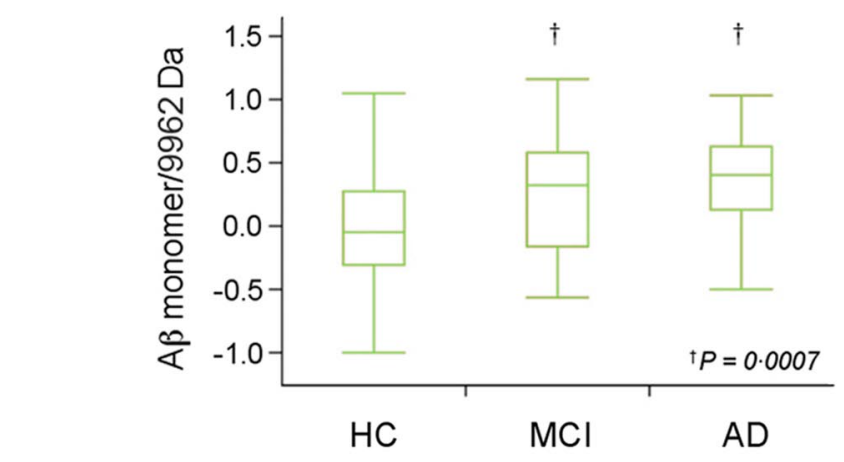

$A \beta$ monomer

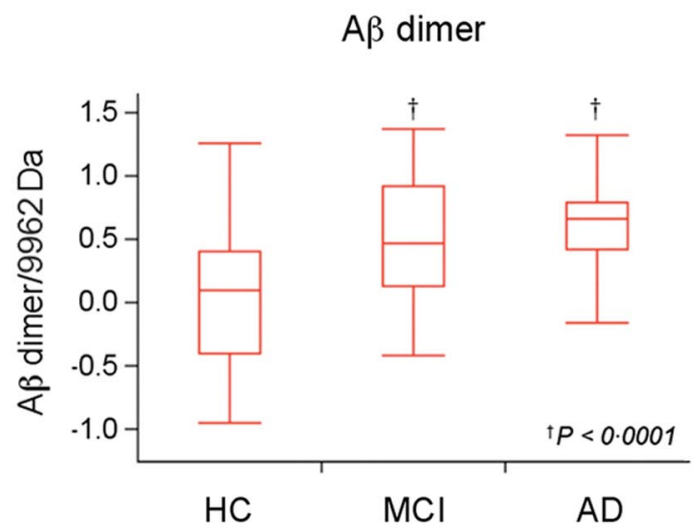

B
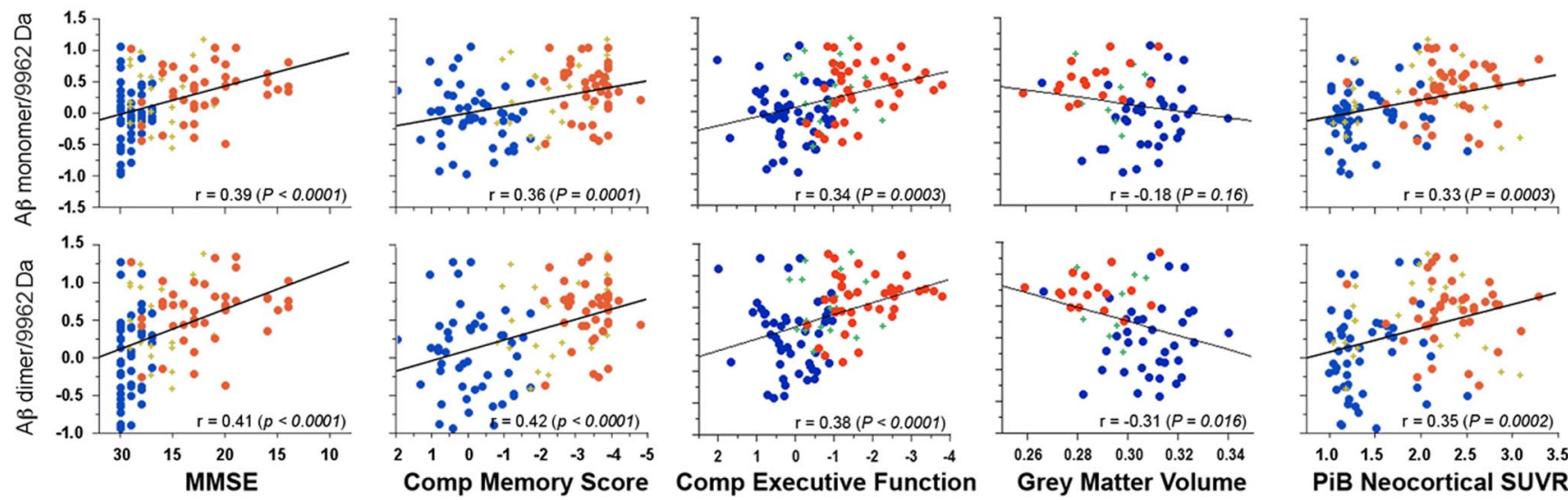

Figure 6. Characteristics and relationship of the ratio of the blood SELDI-TOF MS values with clinical and neuroimaging parameters in 118 participants. Box-and-whiskers plots comparing the respective $\mathrm{A} \beta$ monomer and dimer to $9962 \mathrm{Da}$ ratios in $\mathrm{HC}, \mathrm{MCl}$, and $\mathrm{AD}$ subjects. $A$, A much better separation between the AD and $\mathrm{HC}$ groups is obtained ( $C$ ohen's $d: 0.76$ and 1.03 for monomer and dimer ratios, respectively) than when the peak intensities are examined separately. $A \beta$ monomer and dimer to 9962 Da ratios are highly correlated with clinical, neuropsychometric, and biological markers. $\boldsymbol{B}$, The correlations are better than when either the monomer, the dimer, or the 9962 Da peaks are examined separately. $\mathrm{HC}$, Blue circle; $\mathrm{MCl}$, green + ; $\mathrm{AD}$, red circle.

higher in controls relative to diseased subjects, the correlations are of opposite sign to those of monomeric and dimeric $\mathrm{A} \beta$.

As the $9962 \mathrm{~m} / z$ peak and the $\mathrm{A} \beta$ dimer peak reflect a balance between two different APP processing pathways, i.e., an amyloidogenic pathway and a non-amyloidogenic pathway, we further examined the ability of the ratio of the monomer and dimer to the 9962 Da peak to discriminate between AD and controls. The distinction between $\mathrm{AD}$ and controls for the monomer and dimer ratios was better than when using the peaks intensities independently ( $p=0.0007$ and $<0.0001$, for monomer and dimer ratios respectively) (Fig. $6 A$ ), and the correlations with clinical markers of $\mathrm{AD}$ were also improved: $\mathrm{MMSE}(r=0.39$ and $0.41, p<0.0001$, for monomer and dimer ratios, respectively), memory impairment ( $r=0.36$ and $0.42, p \leq 0.0001$, for monomer and dimer ratios, respectively), executive function ( $r=0.34$ and $0.38, p=$ 0.0003 and $<0.0001$, for monomer and dimer ratios, respectively), gray matter volume $(r=-0.18$ and $-0.31, p=0.16$ and 0.016 , for monomer and dimer ratios, respectively), and brain $\mathrm{A} \beta$ burden as measured by ${ }^{11} \mathrm{C}-\mathrm{PiB}$ PET $(r=0.33$ and $0.35, p=$ 0.0003 and 0.0002 , for monomer and dimer ratios, respectively) (Fig. $6 \mathrm{~B}$ ). This improvement was also reflected in a larger effect size for the ratio compared with the one obtained with the $A \beta$ dimer alone (1.03 and 0.76 , respectively).

\section{Discussion}

The genetics of familial forms of $\mathrm{AD}$ implicates the $\mathrm{A} \beta$ peptide as playing a pivotal role in the development of $\mathrm{AD}$ and $\mathrm{A} \beta$ deposi- tion in the form of amyloid plaque is one of the defining pathological hallmarks of $\mathrm{AD}$. Yet one of the conundrums of $\mathrm{AD}$ research is that plaque burden does not necessarily correlate with disease progression, a finding that has been supported by data using ${ }^{11} \mathrm{C}-\mathrm{PiB}$ PET imaging to show that $\mathrm{A} \beta$ burden does not correlate with cognitive impairment in AD (Rowe et al., 2007), and that $20-30 \%$ of seemingly healthy older controls are defined as $\mathrm{PiB}$ positive indicating significant amyloid pathology is present (Mintun et al., 2006; Rowe et al., 2007; Aizenstein et al., 2008). However, it has been shown that relatively low abundance soluble oligomers better correlate with disease progression (Lue et al., 1999; McLean et al., 1999) and that synaptotoxic A $\beta$ dimers are elevated in AD brains (Shankar et al., 2008). As a result, there is much interest in developing therapeutic and diagnostic strategies targeting soluble oligomers of $\mathrm{A} \beta$.

Before this study there has been no direct detection of $\mathrm{A} \beta$ oligomers in blood which probably reflects limitations in the technology used and in the tissue being examined. None of the $\mathrm{A} \beta$ biomarker protocols currently used clinically, e.g., PiB PET imaging or $\mathrm{A} \beta$ ELISAs were designed to specifically detect such species, although there has been a recent report of an ELISA method against $A \beta$ oligomers (Xia et al., 2009).

We have previously shown that SELDI-MS technology is able to detect an array of $\mathrm{A} \beta$ oligomers and that these oligomers have a high affinity for lipid membranes (Hung et al., 2008). Therefore, while most attempts at identifying blood-based biomarkers 
for $\mathrm{AD}$ have concentrated on plasma with disappointing results (Zetterberg and Blennow, 2006), it is likely that the A $\beta$ oligomers, which have a high affinity for lipid binding, would be found associated with the lipid membranes of the usually discarded CEs. Using SELDI-TOF MS technology it is possible to detect a dimeric form of $\mathrm{A} \beta$ in human blood and show that the levels of the dimer are significantly elevated in $\mathrm{AD}$ (Fig. $2 \mathrm{~B}$ ) and correlate with clinical markers of the disease (Fig. 5).

In the search for potential biomarkers for $\mathrm{AD}$ it has been found that autoantibodies against $\mathrm{A} \beta$ oligomers are decreased in the blood of AD subjects (Moir et al., 2005; Britschgi et al., 2009). In the study by Moir et al. (2005), the decreased autoantibodies were reported to target a specific form of oxidatively modified A $\beta$ caused by a reaction with copper and resulting in covalently cross-linked amyloid protein species, the so-called CAPS. The reaction of $A \beta$ and copper has been shown to lead to the formation of dityrosine cross-linked oligomers of $\mathrm{A} \beta$ (Atwood et al., 2004; Barnham et al., 2004). One consequence of the reduction in autoantibodies is greater accumulation of these $A \beta$ oligomers in the blood. Interestingly, we were able to show that the $\mathrm{A} \beta$ dimer detected in blood had the same MS profile (Fig. $3 B$ ) as a synthetic $\mathrm{A} \beta$ dimer were the $\mathrm{A} \beta$ peptide chains that contain a sulfoxide at residue M35 are covalently crosslinked by a dityrosine moiety.

A peak detected at a $m / z$ of $9962 \mathrm{Da}$ is lower in diseased subjects (Fig. $2 \mathrm{~B}$ ) and is inversely correlated with clinical markers of $\mathrm{AD}$ (Fig. 5). This molecular weight does not correspond to any obvious APP fragment - it is too small to be a fragment resulting from $\beta$-secretase activity, and too big to be the result of $\gamma$-secretase activity-nor does the mass correspond to any $\mathrm{A} \beta$ like aggregate. This suggests that the fragment is generated via an alternative, non-amyloidogenic processing pathway. While definitive identification of this fragment will require isolation and amino acid sequencing, it has previously been reported that the activity of cathepsin $\mathrm{D}$ is decreased in the blood of AD subjects (Straface et al., 2005). Cathepsin D is an aspartyl protease that cleaves APP at a number of different sites (Higaki et al., 1996), including at Ser627, Phe765, Glu766, and Met768. Cleavage at these sites would give rise to a number of $15 \mathrm{kDa}$ fragments; subsequent $\varepsilon$-cleavage of these fragments by $\gamma$-secretase at Met722 would give rise to a $10 \mathrm{kDa}$ fragment. There is also a cathepsin D cleavage site at Val669, subsequent cleavage by $\gamma$-secretase at the $\varepsilon$ site would give rise to a $5 \mathrm{kDa}$ fragment. As can be seen from Table 2 and the cluster analysis (Fig. 2A), a number of related fragments with similar masses are detected as being elevated in the blood of the control subjects including the peak at $9962 \mathrm{Da}$.

The spectrum of APP fragments observed by SELDI-TOF MS in the cluster analysis is consistent with there being two distinct processing pathways for APP, an amyloidogenic pathway which predominates in $\mathrm{AD}$ and a non-amyloidogenic pathway which predominates in healthy subjects (Fig. 2A). Both these pathways occur physiologically and it could be argued that the progression to $\mathrm{AD}$ is the result of a shift in the processing of APP from the non-amyloidogenic to the amyloidogenic pathway. The genetics of early onset AD support this model (Fassbender et al., 2001). The recent publication that $\beta$-secretase activity in platelets is increased in AD compared with controls (Zainaghi et al., 2007; Johnston et al., 2008) is consistent with the amyloidogenic pathway being "favored" in AD.

Given that the onset of the disease may predate clinical symptoms of AD by many years (Price and Morris, 1999), the lack of valid biomarkers has hampered the development and evaluation of effective therapies for AD (Clark et al., 2008). A number of potential $\mathrm{AD}$ therapeutic strategies targeting $\mathrm{A} \beta$ and its oligomers (so called disease-modifying drugs) are currently being investigated, including immunotherapy designed to promote $\mathrm{A} \beta$ clearance (Nicoll et al., 2006), secretase inhibitors, which prevent $\mathrm{A} \beta$ generation (Olson and Albright, 2008), scyllo-inositol, which is reported to inhibit toxic $\mathrm{A} \beta$ oligomers binding to membranes (Nitz et al., 2008), and PBT2-a second generation MPAC that inhibits the formation of toxic $\mathrm{A} \beta$ oligomers (Adlard et al., 2008). The assessment of outcomes of the clinical trials is often difficult to define as they rely on highly variable neuropsychometric tests. To overcome the variability that is inherent in these tests, large sample sizes and long timeframes are required to observe subtle changes in subjects' performance, dramatically increasing the cost of these trials. The ability to detect preclinical or early stage disease through reliable laboratory and neuroimaging biomarkers for $\mathrm{AD}$ would enable more efficient clinical trials to be designed and monitored. Ideally a biomarker should reflect a disease-specific process and be detected in an easily collected tissue.

The most easily accessed tissue is blood and the fractionation procedures we used were deliberately kept simple to reflect the standard protocol used in clinical laboratories worldwide to perform plasma-based assays. In this instance, however, we analyzed the usually discarded membrane-rich CE fraction. The data presented here establishes that disease relevant APP/A $\beta$-based biomarkers are likely to be found in the membrane fraction of blood. Given that the blood borne biomarkers correlate with disease progression they hold the promise of providing a simple yet effective way of monitoring the success or otherwise of the various disease modifying therapies targeting $\mathrm{A} \beta / \mathrm{APP}$ processing.

Because the molecular changes occur well before the phenotypical manifestation of disease, identification of specific biomarkers for particular traits of the pathological process will permit early intervention with disease-modifying medications. Further characterization of the different species in $\mathrm{AD}$ and controls is warranted, while ongoing longitudinal studies will help elucidate how these markers change over time and how they relate to cognitive decline.

\section{References}

Adlard PA, Cherny RA, Finkelstein DI, Gautier E, Robb E, Cortes M, Volitakis I, Liu X, Smith JP, Perez K, Laughton K, Li QX, Charman SA, Nicolazzo JA, Wilkins S, Deleva K, Lynch T, Kok G, Ritchie CW, Tanzi RE, et al. (2008) Rapid restoration of cognition in Alzheimer's transgenic mice with 8-hydroxy quinoline analogs is associated with decreased interstitial Abeta. Neuron 59:43-55.

Aizenstein HJ, Nebes RD, Saxton JA, Price JC, Mathis CA, Tsopelas ND, Ziolko SK, James JA, Snitz BE, Houck PR, Bi W, Cohen AD, Lopresti BJ, DeKosky ST, Halligan EM, Klunk WE (2008) Frequent amyloid deposition without significant cognitive impairment among the elderly. Arch Neurol 65:1509-1517.

Atwood CS, Perry G, Zeng H, Kato Y, Jones WD, Ling KQ, Huang X, Moir RD, Wang D, Sayre LM, Smith MA, Chen SG, Bush AI (2004) Copper mediates dityrosine cross-linking of Alzheimer's amyloid-beta. Biochemistry 43:560-568.

Barnham KJ, Ciccotosto GD, Tickler AK, Ali FE, Smith DG, Williamson NA, Lam YH, Carrington D, Tew D, Kocak G, Volitakis I, Separovic F, Barrow CJ, Wade JD, Masters CL, Cherny RA, Curtain CC, Bush AI, Cappai R (2003) Neurotoxic, redox-competent Alzheimer's beta-amyloid is released from lipid membrane by methionine oxidation. J Biol Chem 278:42959-42965.

Barnham KJ, Haeffner F, Ciccotosto GD, Curtain CC, Tew D, Mavros C, Beyreuther K, Carrington D, Masters CL, Cherny RA, Cappai R, Bush AI (2004) Tyrosine gated electron transfer is key to the toxic mechanism of Alzheimer's disease beta-amyloid. FASEB J 18:1427-1429.

Benjamini Y, Hochberg Y (1995) Controlling the false discovery rate: a 
practical and powerful approach to multiple testing. J R Stat Soc B 57:289-300.

Britschgi M, Olin CE, Johns HT, Takeda-Uchimura Y, LeMieux MC, Rufibach K, Rajadas J, Zhang H, Tomooka B, Robinson WH, Clark CM, Fagan AM, Galasko DR, Holtzman DM, Jutel M, Kaye JA, Lemere CA, Leszek J, Li G, Peskind ER, et al. (2009) Neuroprotective natural antibodies to assemblies of amyloidogenic peptides decrease with normal aging and advancing Alzheimer's disease. Proc Natl Acad Sci U S A 106:12145-12150.

Cappai R, Barnham KJ (2008) Delineating the mechanism of Alzheimer's disease A beta peptide neurotoxicity. Neurochem Res 33:526-532.

Clark CM, Davatzikos C, Borthakur A, Newberg A, Leight S, Lee VM, Trojanowski JQ (2008) Biomarkers for early detection of Alzheimer pathology. Neurosignals 16:11-18.

Collins DL, Zijdenbos AP, Kollokian V, Sled JG, Kabani NJ, Holmes CJ, Evans AC (1998) Design and construction of a realistic digital brain phantom. IEEE Trans Med Imaging 17:463-468.

Fassbender K, Masters C, Beyreuther K (2001) Alzheimer's disease: molecular concepts and therapeutic targets. Naturwissenschaften 88:261-267.

Glabe CG, Kayed R (2006) Common structure and toxic function of amyloid oligomers implies a common mechanism of pathogenesis. Neurology 66:S74-78.

Higaki J, Catalano R, Guzzetta AW, Quon D, Navé JF, Tarnus C, D’Orchymont H, Cordell B (1996) Processing of beta-amyloid precursor protein by cathepsin D. J Biol Chem 271:31885-31893.

Hung LW, Ciccotosto GD, Giannakis E, Tew DJ, Perez K, Masters CL, Cappai R, Wade JD, Barnham KJ (2008) Amyloid-beta peptide (Abeta) neurotoxicity is modulated by the rate of peptide aggregation: Abeta dimers and trimers correlate with neurotoxicity. J Neurosci 28:11950-11958.

Ida N, Hartmann T, Pantel J, Schröder J, Zerfass R, Förstl H, Sandbrink R, Masters CL, Beyreuther K (1996) Analysis of heterogeneous A4 peptides in human cerebrospinal fluid and blood by a newly developed sensitive Western blot assay. J Biol Chem 271:22908-22914.

Johnston JA, Liu WW, Coulson DT, Todd S, Murphy S, Brennan S, Foy CJ, Craig D, Irvine GB, Passmore AP (2008) Platelet beta-secretase activity is increased in Alzheimer's disease. Neurobiol Aging 29:661-668.

Klunk WE, Engler H, Nordberg A, Wang Y, Blomqvist G, Holt DP, Bergström M, Savitcheva I, Huang GF, Estrada S, Ausén B, Debnath ML, Barletta J, Price JC, Sandell J, Lopresti BJ, Wall A, Koivisto P, Antoni G, Mathis CA, Långström B (2004) Imaging brain amyloid in Alzheimer's disease with Pittsburgh Compound-B. Ann Neurol 55:306-319.

Kok WM, Scanlon DB, Karas JA, Tew D, Miles LA, Parker MW, Barnham KJ, Hutton CA (2009) Solid-phase synthesis of homodimeric peptides: preparation of covalently-linked dimers of amyloid-beta peptide. Chem Commun (Camb) 41:6228-6230.

Lue LF, Kuo YM, Roher AE, Brachova L, Shen Y, Sue L, Beach T, Kurth JH, Rydel RE, Rogers J (1999) Soluble amyloid beta peptide concentration as a predictor of synaptic change in Alzheimer's disease. Am J Pathol 155:853-862.

Masters CL, Cappai R, Barnham KJ, Villemagne VL (2006) Molecular mechanisms for Alzheimer's disease: implications for neuroimaging and therapeutics. J Neurochem 97:1700-1725.

McKhann G, Drachman D, Folstein M, Katzman R, Price D, Stadlan EM (1984) Clinical Diagnosis of Alzheimer's Disease: report of the NINCDSADRDA Work Group under the auspices of Department of Health and Human Services Task Force on Alzheimer's Disease. Neurology 34:939-944.

McLean CA, Cherny RA, Fraser FW, Fuller SJ, Smith MJ, Beyreuther K, Bush AI, Masters CL (1999) Soluble pool of A $\beta$ amyloid as a determinant of severity of neurodegeneration in Alzheimer's disease. Ann Neurol 46:860-866.

Mintun MA, Larossa GN, Sheline YI, Dence CS, Lee SY, Mach RH, Klunk WE, Mathis CA, DeKosky ST, Morris JC (2006) [11C]PIB in a nondemented population: potential antecedent marker of Alzheimer disease. Neurology 67:446-452.

Moir RD, Tseitlin KA, Soscia S, Hyman BT, Irizarry MC, Tanzi RE (2005) Autoantibodies to redox-modified oligomeric Abeta are attenuated in the plasma of Alzheimer's disease patients. J Biol Chem 280:17458-17463.

Nicoll JA, Barton E, Boche D, Neal JW, Ferrer I, Thompson P, Vlachouli C,
Wilkinson D, Bayer A, Games D, Seubert P, Schenk D, Holmes C (2006) Abeta species removal after abeta42 immunization. J Neuropathol Exp Neurol 65:1040-1048.

Nitz M, Fenili D, Darabie AA, Wu L, Cousins JE, McLaurin J (2008) Modulation of amyloid-beta aggregation and toxicity by inosose stereoisomers. FEBS J 275:1663-1674

Olson RE, Albright CF (2008) Recent progress in the medicinal chemistry of gamma-secretase inhibitors. Curr Top Med Chem 8:17-33.

Ourselin S, Roche A, Subsol G, Pennec X, Ayache N (2001) Reconstructing a 3D structure from serial histological sections. Image Vis Comput 19:25-31.

Petersen RC, Smith GE, Waring SC, Ivnik RJ, Tangalos EG, Kokmen E (1999) Mild cognitive impairment: clinical characterization and outcome. Arch Neurol 56:303-308.

Pike KE, Savage G, Villemagne VL, Ng S, Moss SA, Maruff P, Mathis CA, Klunk WE, Masters CL, Rowe CC (2007) Beta-amyloid imaging and memory in non-demented individuals: evidence for preclinical Alzheimer's disease. Brain 130:2837-2844.

Price JL, Morris JC (1999) Tangles and plaques in nondemented aging and “preclinical” Alzheimer's disease. Ann Neurol 45:358-368.

Rowe CC, Ng S, Ackermann U, Gong SJ, Pike K, Savage G, Cowie TF, Dickinson KL, Maruff P, Darby D, Smith C, Woodward M, Merory J, Tochon-Danguy H, O'Keefe G, Klunk WE, Mathis CA, Price JC, Masters CL, Villemagne VL (2007) Imaging beta-amyloid burden in aging and dementia. Neurology 68:1718-1725.

Schupf N, Tang MX, Fukuyama H, Manly J, Andrews H, Mehta P, Ravetch J, Mayeux R (2008) Peripheral Abeta subspecies as risk biomarkers of Alzheimer's disease. Proc Natl Acad Sci U S A 105:14052-14057.

Shankar GM, Li S, Mehta TH, Garcia-Munoz A, Shepardson NE, Smith I, Brett FM, Farrell MA, Rowan MJ, Lemere CA, Regan CM, Walsh DM, Sabatini BL, Selkoe DJ (2008) Amyloid-beta protein dimers isolated directly from Alzheimer's brains impair synaptic plasticity and memory. Nat Med 14:837-842.

Sjögren M, Andreasen N, Blennow K (2003) Advances in the detection of Alzheimer's disease-use of cerebrospinal fluid biomarkers. Clin Chim Acta 332:1-10

Skaff O, Jolliffe KA, Hutton CA (2005) Synthesis of the side chain crosslinked tyrosine oligomers dityrosine, trityrosine, and pulcherosine. J Org Chem 70:7353-7363.

Sokal RR, Michener CD (1958) A statistical method for evaluating systematic relationships. Univ Kans Sci Bull 38:1409-1438.

Straface E, Matarrese P, Gambardella L, Vona R, Sgadari A, Silveri MC, Malorni W (2005) Oxidative imbalance and cathepsin D changes as peripheral blood biomarkers of Alzheimer disease: a pilot study. FEBS Lett 579:2759-2766.

Tickler AK, Barrow CJ, Wade JD (2001) Improved preparation of amyloidbeta peptides using DBU as Nalpha-Fmoc deprotection reagent. J Pept Sci $7: 488-494$.

Tzourio-Mazoyer N, Landeau B, Papathanassiou D, Crivello F, Etard O, Delcroix N, Mazoyer B, Joliot M (2002) Automated anatomical labeling of activations in SPM using a macroscopic anatomical parcellation of the MNI MRI single-subject brain. Neuroimage 15:273-289.

Walsh DM, Selkoe DJ (2004) Deciphering the molecular basis of memory failure in Alzheimer's disease. Neuron 44:181-193.

Walsh DM, Klyubin I, Fadeeva JV, Cullen WK, Anwyl R, Wolfe MS, Rowan MJ, Selkoe DJ (2002) Naturally secreted oligomers of amyloid beta protein potently inhibit hippocampal long-term potentiation in vivo. Nature 416:535-539.

Xia W, Yang T, Shankar G, Smith IM, Shen Y, Walsh DM, Selkoe DJ (2009) A specific enzyme-linked immunosorbent assay for measuring betaamyloid protein oligomers in human plasma and brain tissue of patients with Alzheimer disease. Arch Neurol 66:190-199.

Zainaghi IA, Forlenza OV, Gattaz WF (2007) Abnormal APP processing in platelets of patients with Alzheimer's disease: correlations with membrane fluidity and cognitive decline. Psychopharmacology (Berl) 192: 547-553.

Zetterberg H, Blennow K (2006) Plasma Abeta in Alzheimer's disease- up or down? Lancet Neurol 5:638-639. 